$6 \%, 6, n, W, M$

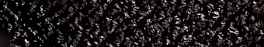

$3+3,4,35$

Pot 3 , w

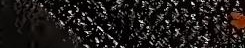

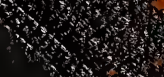

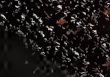

Wus

4

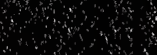

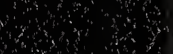





\section{Historic, archived document}

Do not assume content reflects current scientific knowledge, policies, or practices. 


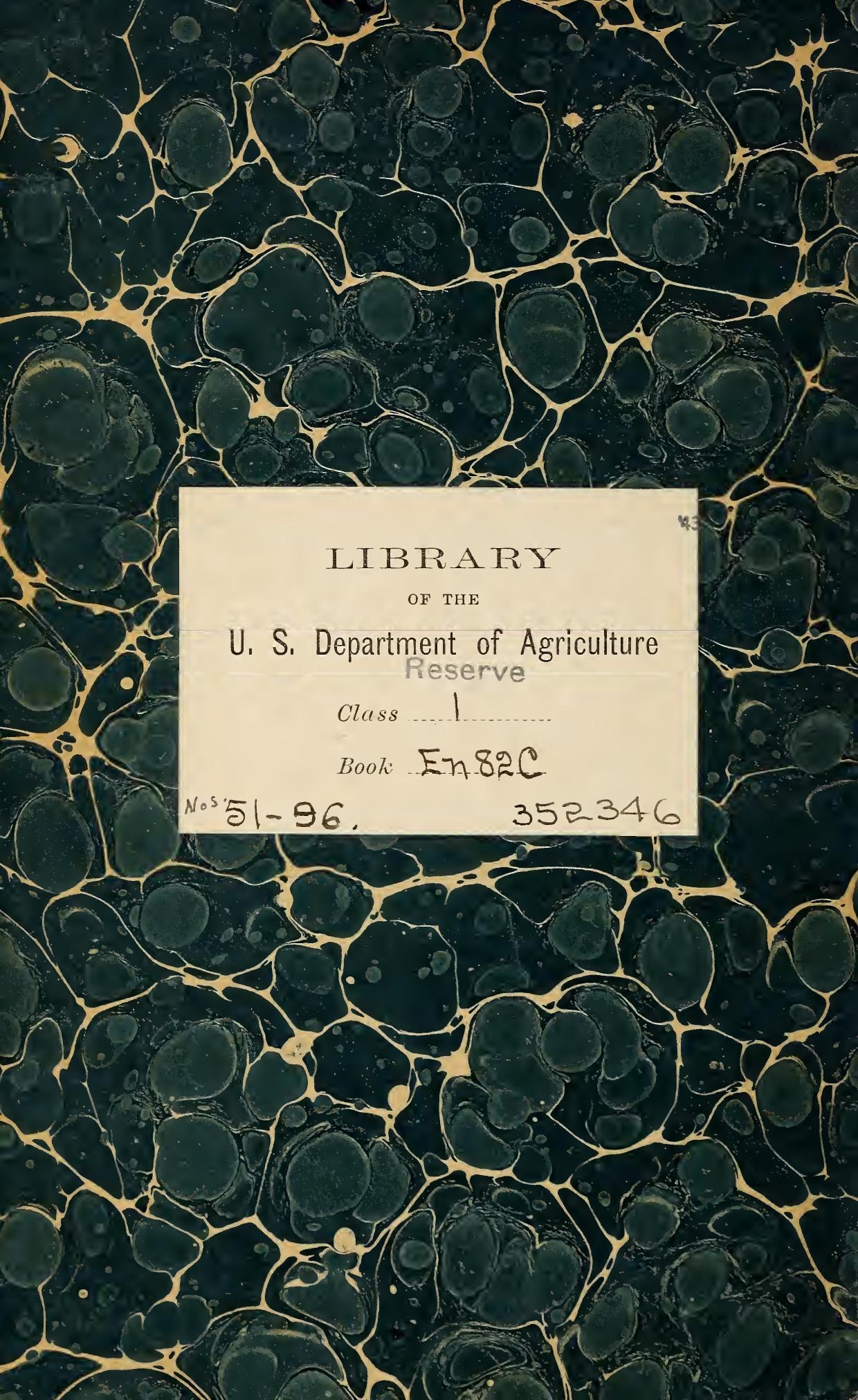




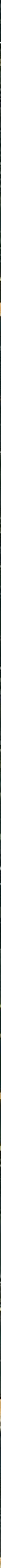





\author{
BUREAU OF ENTOMOLOGY.
}

L. O. HOWARD, Entomologist and Chief of Bureau.

\title{
NOTE ON THE OCCURRENCE OF THE NORTH AMERICAN FEVER TICK ON SHEEP.
}

\section{By W. D. Hunter, In Charge of Coiton Boll Weevil Investigations.}

There are no published records of the finding of specimens of the North American fever tick (Boophilus annulatus Say) on sheep. In fact, it has generally been supposed that this species does not occur on sheep, although Mr. B. H. Ransom has surmised that such might be the case. ${ }^{1}$ In connection with the tick work of the Bureau of Entomology an agent, Mr. J. D. Mitchell, has recently obtained data which indicate a rather general occurrence of the fever tick on sheep. On account of the considerable practical importance of this matter it is thought advisable to publish this preliminary note.

The practical importance of the discovery made by Mr. Mitchell lies in the fact that the dissemination of ticks by sheep may play a very important part in the work of eradication that is now under way. In the general work of the eradication frequent use must be made of the "starvation" plan under which the cattle are removed from pastures for a considerable time. In many parts of the tick-infested area most of the cattle raisers have as many cattle as they can possibly carry on their holdings. To be forced to dispense with the use of a part of the pasture area in many cases would force the sale of a portion of the cattle, perhaps at an unfavorable time for marketing. If, however, it were possible to allow some other kind of live stock to graze on pastures from which ticks are being eradicated according to the starvation plan, the inconvenience and possible loss to the ranchmen would be considerably lessened. Since the North American fever tick has previously not been known to infest sheep, it has been thought that the pastures might be used for grazing these animals. The discoveries made by Mr. Mitchell, however, indicate that the dissemination of fever ticks by sheep is of such practical importance that, at least in the parts of Texas where the matter has been investigated, a pasture would remain infested indefinitely even if the sheep alone were allowed to roam over it. It is not a case of the scattering of the seed ticks from one part of the pasture

${ }^{1}$ Cir. 98, Bureau of Animal Industry, U. S. Dept. Agric., p. 8, October, 1906. 
to another, but a case of the breeding of the ferer ticks on sheep, since in several cases fully engorged females have been found on these animals, and they are now freely depositing eggs.

The following are some of the particulars regarding data obtained up to this time. The matter will be followed up by the Bureau of Entomology, and a further report will be made at the end of the season.

In April, 1907, Mr. A. P. Ward, of Jackson County, Tex., sent to Mr. J. D. Mitchell a number of specimens of Boophilus annulatus that he had taken from a sheep. In this lot there was one engorged female that deposited eggs which have hatched. Mr. Ward's attention was attracted to the matter by seeing this tick hanging in the hair of one fore leg. It was in the act of dropping to the ground for oriposition. At least a dozen other specimens were then collected on this animal. There were five or six nearly engorged adult females, together with several nymphs and larvæ. The sheep upon which these ticks were found had not been sheared this season, although the wool was rather scant on the belly. Nevertheless, the ticks had made their way well up into the thick wool on the sides of the animal. Mr. Ward notes that the sheep was "as oily as she could be." The animal was one which had been left in an isolated field for a month before the ticks were discovered. In moring the herd this one had accidentally been left behind. She was exceedingly active, and there were no indications whatever of any disease. The only fact which would tend to indicate the possibility of disease in this sheep transmitted by the ticks is that she remained in the same place after the herd was remored. It is barely possible that she was left behind on account of weakness brought about by the disease at the time the herd was remored. Howerer, subsequent evidence from other flocks fails to justify the assumption that there may have been any disease in this case.

Early in May, 1907, Mr. J. D. Mitchell examined many sheep in the flock belonging to Mr. Ward. One adult female tick was found, together with six individuals just passing from the nymphal to the adult stage. These were on several different animals, but all located in the ears.

At about the same time three sheep in a flock in Calhoun County were examined by Mrr. Mitchell. Two adult female ticks about ready to drop to the ground and one molting nymph were found on these three animals.

Since that time Mr. Nitchell has examined ten sheep in a large flock belonging to Col. J. C. Warden, whose ranch is in Victoria County, Tex. On two of these sheep specimens of Boophilus annulatus almost fully engorged were found. They were both located on the head, near the base of the ear. Colonel Warden states that late in the summer and fall the ferer ticks cause considerable amnoyance on his sheep. It is necessary to treat them continuously to prevent damage from screw- 
worms, which are attracted by the wound left when the tick detaches itself or by the blood released when one happens to be crushed on the host.

It will be noted that fully engorged specimens of the fever tick have now been found on sheep by Mr. Mitchell in three different flocks in as many counties in southern Texas. It is expected that future observations will show a rather general occurrence on sheep.

There are several points of importance to be determined, as, for instance, whether the offspring of the ticks which have developed on sheep transmit splenetic fever when placed on nonimmune cattle, and whether the sheep become diseased through the agency of the ticks. It is expected that the Bureau of Animal Industry will undertake investigations in the near future bearing on these points. The purpose of this circular is merely to call attention to matters of immediate practical importance.

It may possibly be important to note that there are some peculiar features of the cattle-tick problem in southern Texas this season. Various conditions have caused unusually large numbers of ticks to be - present in the spring. According to the testimony of cattlemen the ticks have never been more abundant in the spring than they are this season. It is barely possible that this excessive abundance may have had something to do with the occurrence of ticks on sheep, and that under different conditions the sheep would not have become infested. Nevertheless, it must be remembered that in that portion of Texas as well as elsewhere the cattle ticks are frequently as numerous in the fall of the year as they have been this spring. In view of these facts it seems evident that it will be absolutely necessary in plans for eradication to exclude sheep from areas in which an attempt is being made to eradicate the ticks.

Approved :

JAMES WILSON,

Secretary of Agriculture.

Washington, D. C., June 19, 1907. 


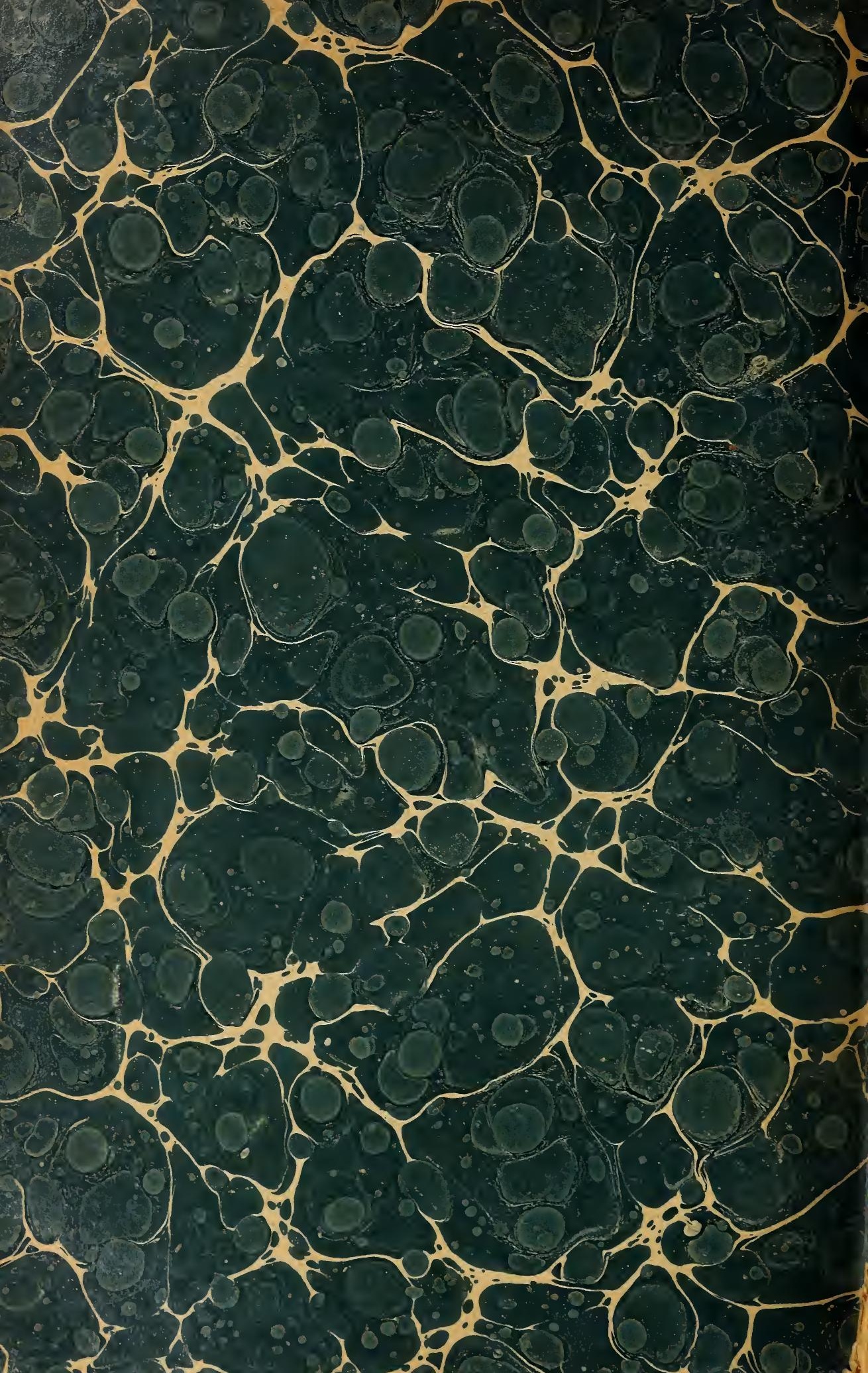




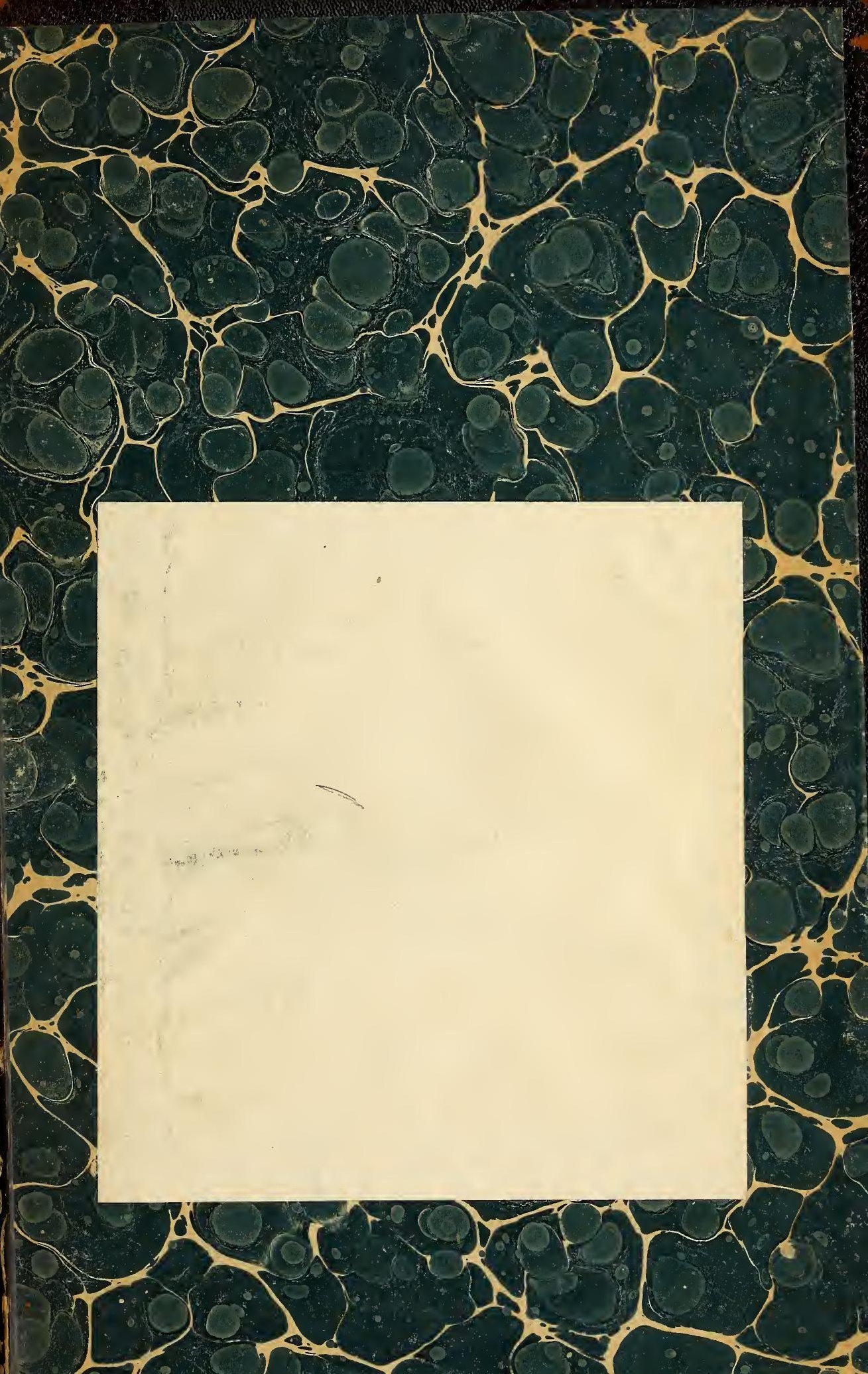




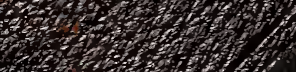

